AN INVESTIGATION OF CATALYTIC ACTIVE PHASE-SUPPORT INTERACTIONS BY IR, NMR AND X-RAY ABSORPTION SPECTROSCOPIES

Progress Report

for the period January 15, 1992 - September 15, 1992

Gary L. Haller

Department of Chemical Engineering

Yale University

New Haven, CT 06520

September, 1992

Prepared for

THE U.S. DEPARTMENT OF ENERGY

AGREEMENT NO. DE-FG02-88ER13836

\title{
NOTICE
}

This report was prepared as an account of work sponsored by the United States Government. Neither the United States nor the Department of Energy, nor any of their employees, nor any of their contractors, subsontractors, or their employees, makes any warranty, express or implied, or assumes any legal liability or responsibility for the accuracy, completness, or usefulness of any information, apparatus, product or process disclosed or represents that its use would not infringe privatelyowned rights. 


\begin{abstract}
Active catalytic phases (metal, mixed metals, oxide or mixed oxides) interacting with oxdde support on which the active phase is dispersed can affect the percentage exposed, the morphology of supported particles, the degree of reducibllity of cations, etc., in a variety of ways. Our objective is to characterize the physical chemistry of the active phase-oxide support interaction by spectroscopic methods and to correlate this structure with catalytic function.

Two catalytic systems and their associated techniques ( $\mathrm{x}$-ray absorption and NMR) are discussed in this progress report. Firstly, the interaction of Pt-Ni supported on silica and L-zeolite are characterized and compared by $x$-ray absorption spectroscopy (EXAFS). Secondly, we present both experimental and calculational developments of NMR for the investigation of amorphous silicaalumina catalysts and/or supports.
\end{abstract}

\title{
I. Introduction and Background
}

Active catalytic phases (metal, mixed metals, oxide or mixed oxides) interacting with oxdde support on which the active phase is dispersed can affect the percentage exposed, the morphology of supported particles, the degree of reducibility of cations, etc., in a variety of ways. Our objective is to characterize the physical chemistry of the active phase-oxdde support interaction by spectroscopic methods and to correlate this structure with catalytic function. An important corollary to this objective is an understanding of the interaction chemistry between the active phase precursors and the oxide supports using the same spectroscopies used to characterize the final active phase.

The support effect on the dispersion and morphology of Pt-Ni clusters supported on silica and L-zeolite is a good example of a metal support interaction. The usual chemisorption and catalytic probes are less useful when both metal components chemisorb and have catalytic activity, but EXAFS is a very useful characterization technique. In the case of $\mathrm{Pt}-\mathrm{Ni} / \mathrm{L}$-zeolite, our preliminary catalytic results indicate that $\mathrm{Ni}$ can have a very significant effect on the $\mathrm{Pt}$ component with respect to stabilizing it against deactivation.

Commercial amorphous silica-aluminas are very important (hydrocracking) catalysts and catalyst (hydrodesulfurization) supports. However, these materials are not only amorphous, but also very heterogeneous. We believe a combination of ${ }^{1} \mathrm{H},{ }^{27} \mathrm{Al}$ and ${ }^{29} \mathrm{Si}$ NMR with two-dimensional, dynamic angle spinning and newly improved Fourier transform analysis will prove useful in their characterization. 
II. Published Reports

In the eight months that this progress report covers, two papers have appeared, one thesis has been officially accepted, one paper has been accepted for publication and three submitted and accepted for publication. All acknowledge DoE support. Of course, these are in part based on previous DoE work and three appeared in our last Progress Report at a different stage of progress. Four are mentioned for the first time. The titles of these seven publications are listed below:

"Temperature Programmed Reduction of Silica Supported Pt/Ni Catalysts Studied by XANES", J. Phys. Chem., 96, 1324 (1992), with A. Jentys, B. J. McHugh and J. A. Lercher.

"Polymerization of Pyrrole over Pd and $\mathrm{SnO}_{2}$ Supported on KL-Zeolite, J. Phys. Chem., 96, 4145, (1992) with G. Larsen and M. Marquez.

"Characterization of Amorphous Silica-Alumina by Solld State NMR and Model Catalytic Reactions", C. Y. Lin, Ph. D. Thesis, Yale University, 1992.

"A XANES-TPR Study of Pt-Re/ $\mathrm{Al}_{2} \mathrm{O}_{3}$ Catalysts," accepted, J. Phys .Chem., with F. Hilbrig and C. Michel.

"The Effect of Preparation Method on Metal-Support Interaction in Pd/L-zeolite Catalysts," to be published in the Proc. 10th Intern. Congr. Catal., Budapest, July 1992, with G. Larsen.

"Characterization of Pt-Ni/KL-Zeolite Bimetallic Catalysts by Chemisorption, Catalysis and X-ray Absorption," to be published in the Proc. 9th Intern. Zeolite Conf., Montreal, July, 1992.

"The Formation of Metallic Particles During Temperature Programmed Reduction of Sillca Supported Pt and Ni Chlorides", accepted, J. Phys. Chem., with A. Jentrys and J. A. Lercher.

\section{Progress Review}

\section{A. The Characterization of Pt-Ni Btmetallic Clusters on $\mathrm{SiO}_{2}$ and L-Zeolite}

We have performed a comparative X-ray absorption investigation of Pt-Ni on $\mathrm{SiO}_{2}[1,2]$ and $\mathrm{L}$-zeolite [3]. In both cases the catalysts were prepared by colmpregnation to incipient wetness. On the $\mathrm{SiO}_{2}$ support, $\mathrm{PtCl}_{4}$ and $\mathrm{NiCl}_{2} \cdot 6 \mathrm{H}_{2} \mathrm{O}$ were the precursors while in the case of L-zeolite $\mathrm{Pt}\left(\mathrm{NH}_{3}\right)_{4}\left(\mathrm{NO}_{3}\right)_{2}$ and $\mathrm{NI}\left(\mathrm{NO}_{3}\right)_{3}$ were used. A selection of our EXAFS results are shown in Table 1 below. 
Table 1. Modeled EXAFr coordination number $N \mathbf{X}-\mathrm{Y}$ and $\mathrm{RX}-\mathrm{Y}$ (where $\mathrm{X}$ is the absorber and $Y$ the scatterc

\begin{tabular}{|c|c|c|c|c|c|c|c|c|}
\hline Catalyst & NPt-Pt & NPt-N1 & NNi-Ni & NN1-Pt & RPt-Pt & RPt-Ni & RNi-Ni & RNi-Pt \\
\hline $\mathrm{Pt} / \mathrm{SiO}_{2}$ & 10.6 & - & - & - & 2.77 & - & - & - \\
\hline $\mathrm{Pt} / \mathrm{KL}$ & 7.1 & - & - & - & 2.77 & - & - & - \\
\hline $0.70 \mathrm{Pt}-\mathrm{Ni} / \mathrm{SiO}_{2}$ & 6.3 & 4.2 & 4.4 & 8.6 & 2.76 & 2.70 & 2.60 & 2.70 \\
\hline $0.70 \mathrm{Pt}-\mathrm{Ni} / \mathrm{KL}$ & 6.7 & 0.6 & 2.3 & 4.9 & 2.75 & 2.69 & 2.58 & 2.69 \\
\hline $0.50 \mathrm{Pt}-\mathrm{Ni} / \mathrm{SiO}_{2}$ & 3.8 & 8.1 & 4.1 & 8.3 & 2.73 & 2.71 & 2.59 & 2.71 \\
\hline $0.53 \mathrm{Pt}-\mathrm{Ni} / \mathrm{KL}$ & 4.1 & 1.1 & 2.9 & 3.7 & 2.73 & 2.68 & 2.57 & 2.68 \\
\hline
\end{tabular}

It can be immedlately seen that there are several differences between the two supports. Generally, the dispersions are poor on the $\mathrm{SiO}_{2}\left(22 \%\right.$ by $\mathrm{H}_{2}$ chemisorption on the $\mathrm{Pt} / \mathrm{SiO}_{2}$ sample compared to $58 \%$ on $\mathrm{Pt} / \mathrm{KL}$ ). However, of more interest is the effect of $\mathrm{NI}$ on the apparent dispersion measured by EXAFS. We can take $\mathrm{NPt}_{\mathrm{N} I}+\mathrm{NPt}_{\mathrm{N} \text { I }}$ as a measure of this effect. On the silfca and L-zeolite supported samples, respectively, it increases on silica from $10.6 \sim 10.5<11.9$ and decreases on L-zeolite 7.1 7.3>5.2. Thus, on both silica and L-zeolite the dispersion does not seem to be much affected when Pt is the major component, but as the composition approaches 50/50, the dispersion on silica appears to decrease while in L-zeolite it appears to increase. In both cases, $\mathrm{R}_{\mathrm{Ni}-\mathrm{NI}}$ is grearer

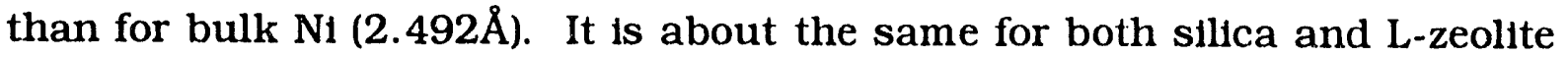
suggesting metal-metal interaction in both cases. However, in the case of the 50 at \% Pt on sllica, coordination numbers are essentially what would be expected for the bulk PtNi intermetallic compound. (At higher ratios of $\mathrm{Ni} / \mathrm{Pt}$, there is evidence for $\mathrm{PtNi}$ and a separate phase, which is either $\mathrm{Ni}$ or $\mathrm{Ni}_{3} \mathrm{Pt}$, is formed.) On L-zeolite, the coordination numbers do not conform to any simple model. The fact that $\mathrm{NPt}_{\mathrm{N} \text { I }}$ does not equal $\mathrm{N}_{\mathrm{Ni} \text {-Pt }}$ (as it should for a 50/50 composition) indicates that there is a problem in the analysis, but whatever the problem here, there is no evidence for a PtNi intermetallic phase and using of the catalytic probe of cyclopropane hydrogenation/hydrogenolysis (see last report), we can rule out a separate Ni phase. 
One of our objectives, in the case of the L-zeolite supported catalysts, is to test the stabllity of the Pt versus the Pt-Ni with regard to deactivation and selectivity. It has been reported by Iglesia and Baumgartner $[4,5]$ that what makes $\mathrm{Pt} / \mathrm{L}$-zeolite unique is its stability against deactivation by coking. It is certainly superior to Pt on other supports, but there is still deactivation leaving room for further improvement.

A selection of results for $\mathrm{n}$-hexane conversion to benzene is presented below in Table 2. Four catalysts with a Pt loading about constant at $5 \mathrm{wt} \%$ were used and three of these had added Ni. The catalysts code indicates the atomic fraction which is $\mathrm{Pt}$ which was varied from 1.0 to 0.44 .

Table 2. Conversion and selectivity on $n$-hexane reaction at $\mathrm{T}=753 \mathrm{~K}, \mathrm{P}_{\mathrm{H}_{2}}=33.8$ $\mathrm{kPa}, \mathrm{Pn}_{\mathrm{n}} \mathrm{C} 6=4.2 \mathrm{kPa}$ ufter $75 \mathrm{~min}$ on stream.

\begin{tabular}{cccccccc}
\hline Catalyst & \%Conv. & $\mathrm{C}_{1}$ & $\mathrm{C}_{2}-\mathrm{C}_{5}$ & $\mathrm{C}_{6}=$ & $\mathrm{Bz}$ & $\mathrm{S}_{\mathrm{Bz}}$ & $\mathrm{R}^{\mathrm{a}}$ \\
\cline { 2 - 8 } & \multicolumn{7}{c}{ Low Conversion } \\
\hline Pt & $10.3^{\mathrm{b}}$ & 0.6 & - & 4.4 & 5.3 & 0.51 & 52 \\
$0.70 \mathrm{Pt}-\mathrm{N} 1$ & $8.1^{\mathrm{b}}$ & 0.5 & - & 2.9 & 4.7 & 0.58 & 45 \\
$0.53 \mathrm{Pt}-\mathrm{N} 1$ & $6.3^{\mathrm{b}}$ & 0.4 & - & 2.8 & 3.1 & 0.49 & 44 \\
$0.44 \mathrm{Pt}-\mathrm{N} 1$ & $5.4^{\mathrm{b}}$ & 0.4 & - & 2.4 & 2.6 & 0.48 & 43 \\
\hline & & \multicolumn{7}{c}{ High Conversion } & & & \\
\hline Pt & 39.6 & 4.8 & - & - & 34.8 & 0.88 & 36 \\
$0.70 \mathrm{Pt}-\mathrm{N} 1$ & 39.8 & 5.3 & 0.3 & 0.1 & 34.1 & 0.86 & 42 \\
$0.53 \mathrm{Pt}-\mathrm{N} 1$ & 54.4 & 7.5 & 0.4 & - & 46.5 & 0.85 & 50 \\
$0.44 \mathrm{Pt}-\mathrm{N} 1$ & 56.1 & 9.0 & 1.0 & - & 46.1 & 0.82 & 52 \\
\hline
\end{tabular}

a $R$ is the relative activity measured as the conversion after 135 minutes on stream relative to 15 minutes on stream.

bTreating this as a differential conversion, the turnover frequencies are estimated to be $0.14,0.14,0.11$ and $0.063 \mathrm{~s}^{-1}$, respectively, at the conditions given.

At low conversion there does not seem to be much effect of the Ni. At the lowest Pt/Ni ratio the turnover frequency is only about half that for pure Pt and both the selectivity and stability (based on the degree of deactivation between 15 and 135 minutes) have diminished slightly. However, at high conversion, the 
story is quite different. The selectivity does decrease some (from 0.88 to 0.82 ) but the stability it substantially improved increasing more than $40 \%$. This is a very important finding. It is likely that the stabllization may be even more significant at the high pressure conditions used in commercial practice.

B. NMR Development for Analysis of Catalysts and Catalyst Supports

We are pursuing two improvements in the applications of NMR to the characterization of catalysts. One of these is an experimental technique, 1.e., dynamic angle spinning (DAS) NMR. This technique is a new approach for obtaining high resolution spectra of quadupolar nuclei, e.g., ${ }^{27} \mathrm{Al}$. (We have discussed DAS in some detail in a supplementary proposal which was funded and this will not be repeated here.)

Our second approach is calculational. As is the case in all Fourier spectroscoples, the fast Fourier transform (FFT) of the free induction decay (FID) results in certain information loss when transforming from the time to spectral domain. Typically a filtering window (such as a simple exponential multiplication known as line broadening) is applied before spectral reconstruction to limit noise transmission into the spectrum, but this necessarily degrades resolution. A second common calculational problem is that the FID cannot be completely acquired, often because of a very long relaxation time of the NMR resonance. The FFT calculation then gives a spectrum with severe sidelobes (truncation notse). The Maximun Entropy (MEM) and Linear Prediction (LPM) methods of digital signal processing are newly developed (for NMR) techniques for spectral reconstruction and deconvolution which we are trying to apply to NMR of catalysts. MEM aims to avoid problems associated with the FFT calculation by attempting to select a spectrum whose inverse Fourier transform fits the FID to within the noise level (removes line broadening degradation of resolution). LPM discriminates between real signals and noise by applying the principle of linear prediction in the time domain and applying Lorentzian models to the linear prediction solutions (removes truncation noise).

We have acquired DAS probe and are learning how to use it. As a developmental alumina sample, we are using $\beta$ "-alumina $\left(\mathrm{Na}_{2} \mathrm{O}\right) \times\left(11 \mathrm{Al}_{2} \mathrm{O}_{3}\right)$ where typically $1.15<x<1.30$. This material is a solid electrolyte (which we are using in anoiher project) and it has two conventent NMR nuclel $\left({ }^{23} \mathrm{Na}\right.$ and $\left.{ }^{27} \mathrm{Al}\right)$. The former is reasonably easy to tune up the DAS probe and practice our technique, see Figure 1, and the latter is the nucleus of ultimate interest in our study of amorphous silica-aluminas. 


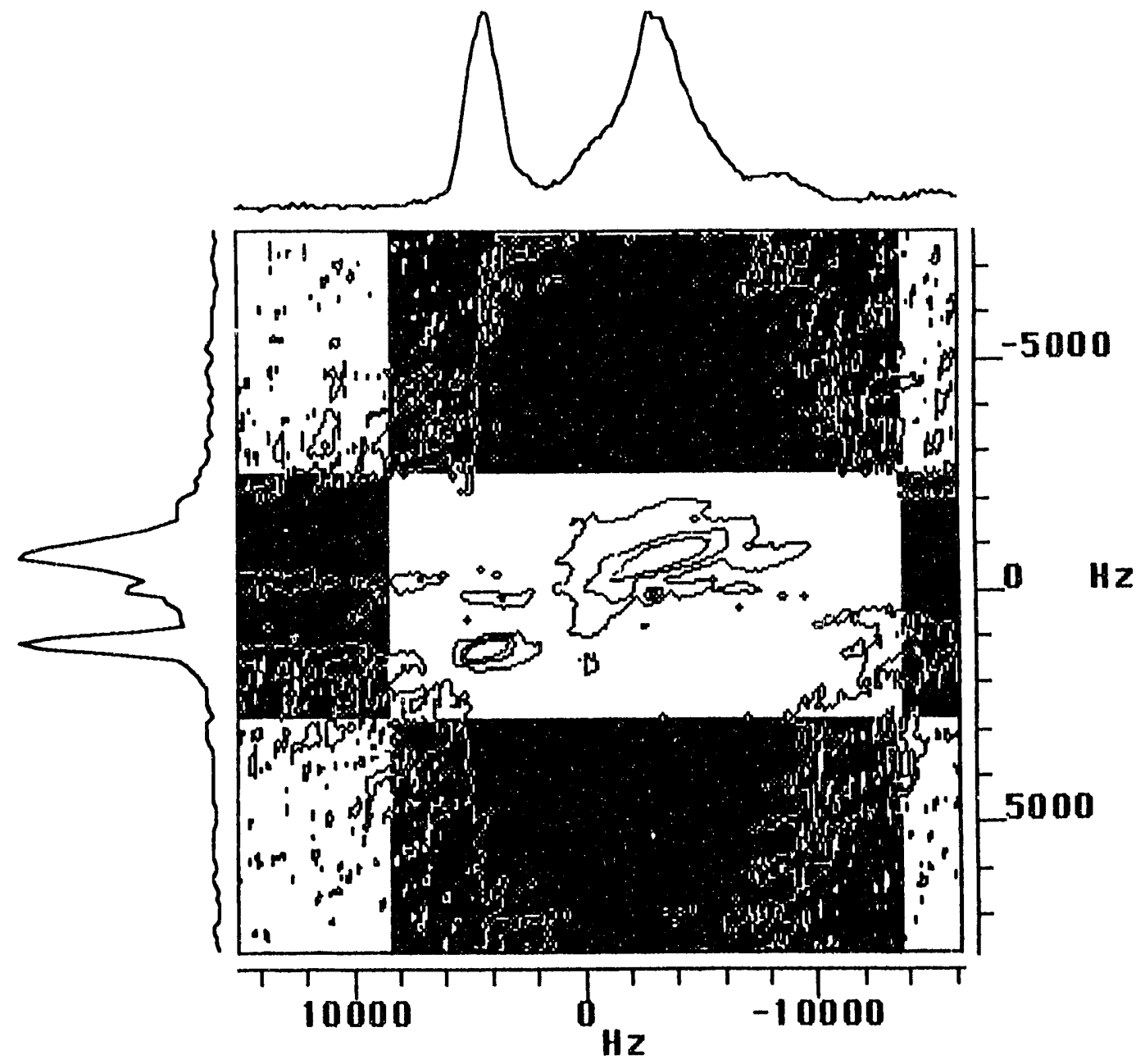

Figure 1: The magic angle spinning (MAS, top of figure) and dynamics angle spinning (DAS, left side of figure) spectrum of ${ }^{23} \mathrm{Na}$ in $\beta$ "-alumina. Note that even though the scale for the DAS is expanded by a factor of two over the MAS spectrum, the line width is still substantially reduced the shoulder between the two maln peaks has a vastly improved resolution. 
We have not completed our analysis of $\beta$ "-alumina from elther the ${ }^{23} \mathrm{Na}$ or ${ }^{27} \mathrm{Al}$ NMR point of view, but it is worth mentioning some the interesting preliminary observations. To convert the $\beta$ "-alumina into a proton conductor (our need in the other project), a portion or all of the $\mathrm{Na}$ is lon exchanged with $\mathrm{NH}_{4}{ }^{+}$. We observe two separate tetrahedral ${ }^{27} \mathrm{Al}$ NMR peaks in the original $\beta$ "-alumina, and one of these disappears after $\mathrm{NH}_{4}{ }^{+}$exchange. We have also found that we can observe the ${ }^{14} \mathrm{~N}$ NMR spectrum. All of this is very encouraging both for the general development of characterization of aluminas and for the specific characterization of the $\beta$ "-alumina.

We conclude with an exmple of the MEM deconvolution of a commercial $45 \mathrm{wt} \% \mathrm{SiO}_{2}-55 \mathrm{wt} \% \mathrm{Al}_{2} \mathrm{O}_{3}$ support. We have a series of these samples which all have the same nominal composition, but significant differnent acidities and support properties. In Table 3 below we show the analysis of silica and one of the $45 \mathrm{wt} \% \mathrm{SiO}_{2}-55 \mathrm{wt} \% \mathrm{Al}_{2} \mathrm{O}_{3}$ supports.

Table 3. Deconvolution of ${ }^{29} \mathrm{~S} 1 \mathrm{NMR}$ peaks into structural components.

\begin{tabular}{|c|c|c|c|c|c|c|c|}
\hline \multicolumn{8}{|c|}{$\mathrm{Si}\left(\mathrm{Si}_{2} \mathrm{Al}_{2}\right) \quad \mathrm{Si}\left(\mathrm{SiAl}_{3}\right)$} \\
\hline ppm & -108 & -104 & -94 & & & & \\
\hline intensity & 100 & 9.2 & 1.7 & & & & \\
\hline \multicolumn{8}{|l|}{$\mathrm{SiO}_{2} \mathrm{Al}_{2} \mathrm{O}_{3}$} \\
\hline ppm & -108 & -104 & -94 & -98 & -90 & -86 & -82 \\
\hline intensity & 100 & 4.2 & 3.0 & 17.6 & 17.3 & 5.2 & 5.8 \\
\hline
\end{tabular}

We have not assigned the three structural components of silica, but it is obvious that there exists a pure sllica component of the mixed oxide. Given the relative amounst of the interbonding components, e.g., $\mathrm{Si}_{1}\left(\mathrm{Si}_{3} \mathrm{Al}\right)$ which implies tetrahedral bonding with three Si-O- and one Al-O- ligands, one can also deducs that there exdsts a separate alumina component by mass balance. However, with both the ${ }^{29} \mathrm{SI}$ and ${ }^{27} \mathrm{Al} \mathrm{NMR}$ spectra and resolution into the interbonded components (from the ${ }^{29} \mathrm{~S} 1 \mathrm{NMR}$ ) and the tetrahedral/octahedral alumina sites (from ${ }^{27} \mathrm{Al} \mathrm{NMR}$ ) and two-dimentional proton-Al and proton-S1 spectra, we believe we will have a powerful analysis tool for these complex oxide mixtures. 


\section{References}

1. A. Jentys, G. J. McHugh, G. L. Haller and J. A. Lercher, J. Phys. Chem., $\underline{96}, 1324$ (1992).

2. A. Jentys, G. L. Haller and J. A. Lercher, J. Phys. Chem., accepted for publication.

3. G. Larsen and G. L. Haller, "Characterization of Pt-N1/KL-Zeoltia Bimetallic Catalysts by Chemisorption, Catalysis and X-ray Absorption," to be published in the Proc. 9th Intern. Zeoltie Conf., Montreal, July, 1992.

4. E. Iglesia and J. E. Baumgartner, "Inhibited Deactivation of Pt Sites and Selective Dehydrocyclization of n-Heptane within L-Zeolite Channels", to be published, Proc. 9th Intern. Zeolite Conf., Montreal, July, 1992.

5. E. Iglesia and J. E. Baumgartner, "A Mechanistic Proposal for Alkane Dehydrocyclization Rates on Pt/L-zeolite. Inhibited Deactivation of Pt Sites within Zeolite Channels", to be published, Proc. 10th Intern. Congr. Catal., Budapest, July, 1992. 

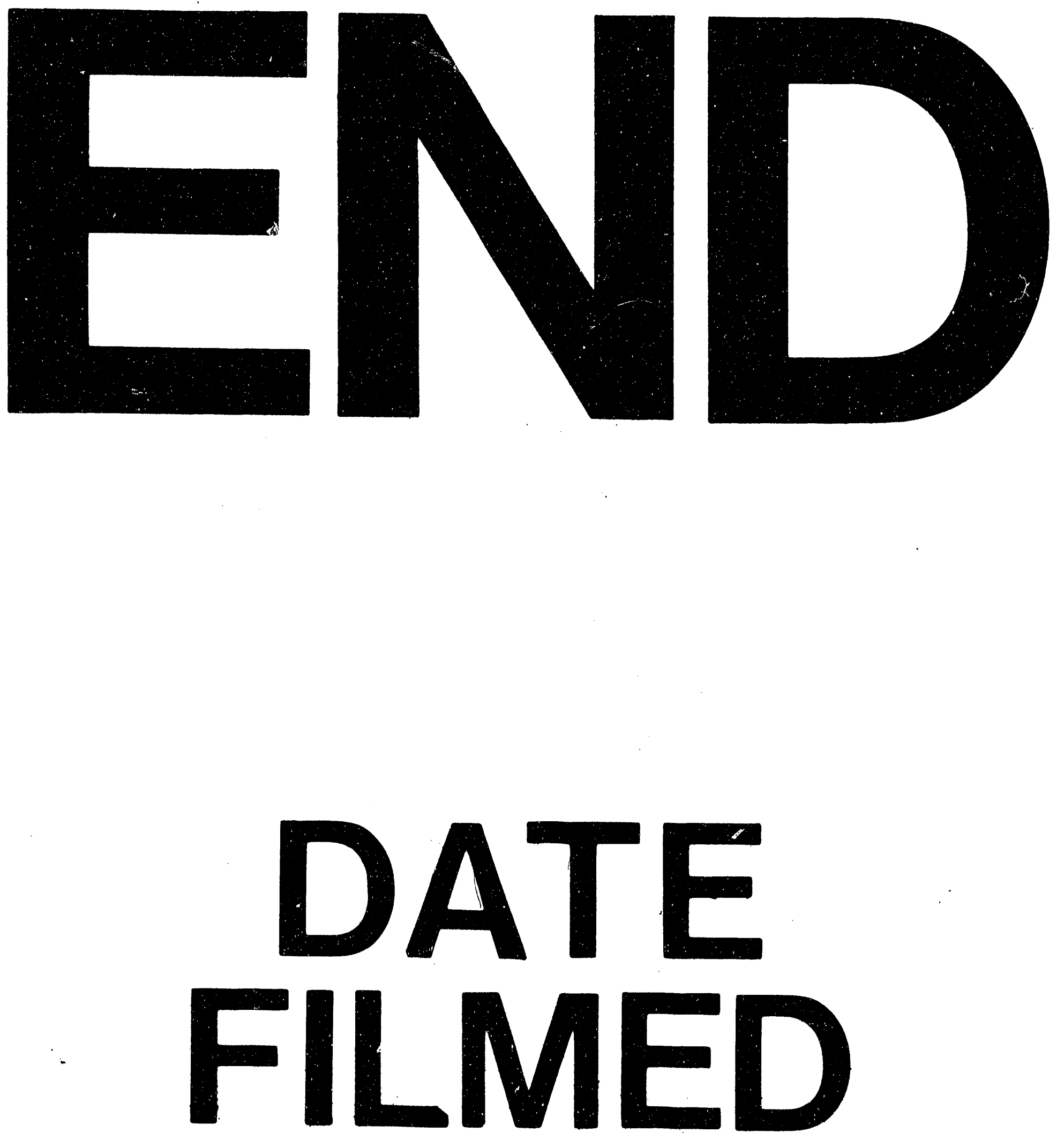

1

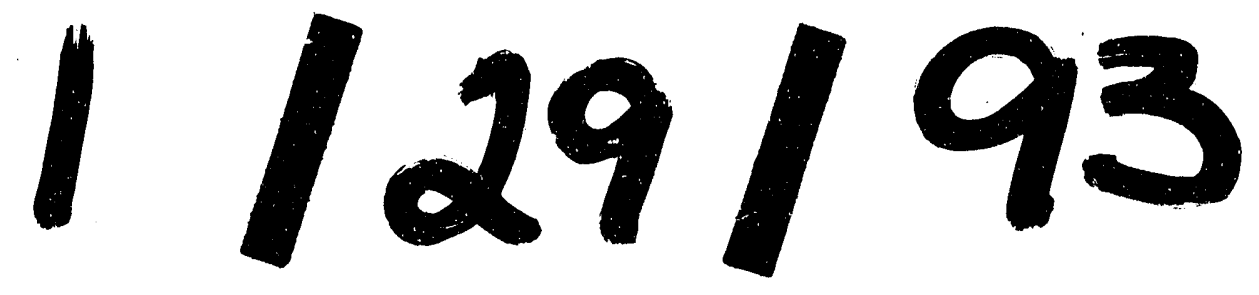


